\title{
Good quality of life before cardiac arrest predicts good quality
}

\section{of life after resuscitation}

\section{Hellevuo, $\mathrm{H}$.}

2018-04

Hellevuo , H , Sainio , M , Huhtala , H , Olkkola , K T , Tenhunen , J \& Hoppu , S 2018 , ' Good quality of life before cardiac arrest predicts good quality of life after resuscitation ' , Acta Anaesthesiologica Scandinavica , vol. 62 , no. 4 , pp. 515-521 . https://doi.org/10.1111/aas.13065

http://hdl.handle.net/10138/321372

https://doi.org/10.1111/aas.13065

unspecified

acceptedVersion

Downloaded from Helda, University of Helsinki institutional repository.

This is an electronic reprint of the original article.

This reprint may differ from the original in pagination and typographic detail.

Please cite the original version. 
1 Good quality of life before cardiac arrest predicts good quality of life after

2 resuscitation

3 Short title: Quality of life remains good after CA

4

5 Heidi Hellevuo ${ }^{1, *}$, Marko Sainio ${ }^{1,2}$, Heini Huhtala ${ }^{3}$, Klaus T Olkkola ${ }^{4}$, Jyrki Tenhunen ${ }^{5}$, Sanna

$6 \mathrm{Hoppu}^{1}$

7 1 Department of Intensive Care Medicine, Tampere University Hospital and University of Tampere, PO Box 2000, FI-

833521 Tampere, Finland

$9 \quad{ }^{2}$ Emergency Medical Services, Department of Emergency Medicine, University of Turku and Turku University Hospital,

10 PO Box 52, FI-20521 Turku, Finland

$11{ }^{3}$ Faculty of Social Sciences, University of Tampere, P.O Box 100, FI-33014 Tampere, Finland

${ }^{4}$ Department of Anaesthesiology, Intensive Care and Pain Medicine, University of Helsinki and Helsinki University Hospital, PO Box 340, FI-00029 HUS, Helsinki, Finland

${ }^{5}$ Department of Surgical Sciences, Anaesthesiology and Intensive Care, Uppsala University, SE 75185 Uppsala, Sweden

*Corresponding author:

Heidi Hellevuo, MD, Department of Intensive Care Medicine, Tampere University Hospital, PO Box 2000, FI-33521 Tampere, Finland. Phone +358 505873296. Fax: +358 331165444

Heidi.Hellevuo@fimnet.fi

Keywords: Quality of Life; Cardiopulmonary Resuscitation; Out-of-Hospital Cardiac Arrest; Inhospital Cardiac Arrest

\section{Word count: 2164 (manuscript), 188 (abstract)}

Clinicaltrials.gov number: NCT00951704 (https://clinicaltrials.gov/ct2/show/NCT00951704)

Relevant conflicts of interests: Dr. Jyrki Tenhunen has been a member of the SuPAR-Symposium organizing committee for SuPARnostic (Virogates, Copenhagen, Denmark) and co-founder and shareholder of SenSem Technologies (Tampere, Finland) and Medieta Ltd (Helsinki, Finland). 


\section{Abstract}

Background: The survival rate of cardiac arrest (CA) patients is increasing. Our aim was to compare the quality of life (QoL) before and after CA and analyse the factors associated with outcome.

Methods: During the years 2009-2011 all adult CA patients admitted to Tampere University Hospital ICU were included in a retrospective follow-up study if surviving to discharge and returning a questionnaire after six months. Data on patient demographics and pre-arrest quality of life were retrieved from medical records. Data are given as means $(\mathrm{SD})$ or medians $\left(\mathrm{Q}_{1}, \mathrm{Q}_{3}\right)$. We used logistic regression to identify factors associated with better QoL after CA.

Results: Six months after CA 36\% (79/222) were alive and 70\% (55/79) of those patients completed the follow-up EuroQoL (EQ-5D) quality of life questionnaire. Median values for the EQ5D before and after CA were $0.89[0.63,1]$ and $0.89[0.62,1]$ respectively $(p=0.75)$. Only the EQ5D prior to CA was associated with better quality of life afterwards (OR 1.2; 95\% CI 1.0 - 1.3; $\mathrm{p}=0.02)$.

7 Conclusions: Quality of life remained good after CA especially in those patients who had good quality of life before the incident. 


\section{Introduction}

Although the survival rate of cardiac arrest (CA) patients may be increasing at least in expert centres, wide variation between centres persists. ${ }^{1}$ Reports suggest that cardiac arrest survivors have good or at least acceptable quality of life. ${ }^{2-6}$ Factors predicting better survival at hospital discharge and good quality of life are ventricular fibrillation (VF) as an initial rhythm and short delay to the return of spontaneous circulation (ROSC). ${ }^{7}$

Quality of life is a complex and multidimensional term based on four different elements, namely socioeconomic factors, health and ability to function in daily living, self-awareness and life satisfaction. ${ }^{8}$ The term health-related quality of life (HRQoL) was coined for research purposes, comprising mental, physical and social components of well-being. ${ }^{9,10}$ Numerous different scales can measure quality of life, ${ }^{11-13}$ many of which have been used to analyse quality of life after CA. ${ }^{2}$ In the 1990's the EuroQoL Group developed a quality of life questionnaire based on five domains of everyday living and self-care. ${ }^{10}$ EuroQoL (EQ-5D) has also been used to report CA patients' quality of life. ${ }^{13-15}$ Quality of Life Index (EQIndex) is calculated from the scores of the five domains given by the patient. The range of the score varies from 0 to 1,1 being the best possible quality of life.

This study was aimed to assess the quality of life before and six months after CA using EuroQoL (EQ-5D) questionnaire as a health-related quality of life (HRQoL) scale (primary endpoint). We also wanted to identify possible factors associated with good quality of life (secondary endpoint). 


\section{Methods}

Study design

This retrospective observational study was approved by Pirkanmaa Hospital District Science Center and the Ethics Committee of Tampere University Hospital (Approval no: R08116, 22.2.2011; clinicaltrials.gov NCT00951704). Data on the EuroQoL (EQ-5D) questionnaire before and after CA, medical histories, cause of CA, initial rhythm, return of spontaneous circulation (ROSC), the possible use of therapeutic hypothermia $(\mathrm{TH})$, other treatments or procedures undertaken (e.g. coronary artery bypass surgery $(\mathrm{CABG})$, percutaneous coronary intervention (PCI) or implantable cardioverter-defibrillator (ICD)/cardiac pacemakers (PAMA) implanted) were collected retrospectively from patients' medical files. Charlson's weighted index of comorbidities $(\mathrm{CCI})^{16}$ and estimated ten-year survival percentages were calculated using the medical histories.

\section{Source population}

From 1.1.2009 to 31.12.2011 we screened all adult patients admitted to ICU after successful resuscitation from in-hospital cardiac arrest (IHCA) or out-of-hospital cardiac arrest (OHCA). Those successfully resuscitated and alive six months after resuscitation received the EQ-5D questionnaire by mail and patients who responded to the follow-up EQ-5D questionnaire constituted the study population.

\section{Hospital and Intensive Care Unit}

Details of Tampere University Hospital (Tays) and incidence of IHCA have been published in our previous study. ${ }^{17}$ The incidence of OHCA in Tampere region is 52/100,000/year. ${ }^{18}$ The mixed ICU has 22 beds, 12 primarily reserved for critically ill patients. The remaining beds provide a high dependency unit with special monitoring and treatment for patients with single organ dysfunction. 
Quality of life before and after resuscitation was measured on EuroQoL (EQ-5D), with five dimensions of quality of life (mobility, self-care, usual activities, pain/discomfort and anxiety/depression) assessed in one simple score (EQIndex). The version of EQ-5D questionnaire used in this study has three grades in each dimension: no / some / major problems on the dimensions describing quality of life. ${ }^{11}$ Score one equals full health and zero death in the EQIndex. A change of 0.05 points is considered significant. The second part of the questionnaire is a selfrated visual analogue scale (VAS) ranging from 0 to 100,100 being the best possible overall health. In this study VAS was omitted from the analysis due to missing data. All patients admitted to ICU were interviewed with EuroQoL (EQ-5D) questionnaire upon arrival or later during the stay, depending on the condition of the patient. If the patient was too sick to respond, the next of kin served as a reliable proxy. ${ }^{19,20}$ Therefore the EQ-5D questionnaire was chosen as a method to report quality of life after CA.

The Charlson Comorbidity Index (CCI) was used to characterise the burden of diseases. ${ }^{16}$ International Classification of Diseases (ICD) diagnosis codes were used to calculate CCI. Diagnoses included in the score in weight category 1 are myocardial infarction, congestive heart failure, peripheral vascular disease, cerebrovascular disease, dementia, chronic pulmonary disease, connective tissue disease, ulcer disease, mild liver disease and diabetes. Weight category 2 includes hemiplegia, moderate and severe renal disease, diabetes with end-organ damage, any tumour, leukaemia and lymphoma. Weight category 3 includes moderate and severe liver diseases. Metastatic tumours and AIDS have weight 6 . The weight in each category is associated with the adjusted risk of mortality or resource use. A patient's comorbidity score is formed by summing all weight results. No comorbidities are scored as 0 . Charlson's index has been shown to predict hospital mortality in critically ill patients and also 1-year survival. ${ }^{22-24}$ Charlson Comorbidity Index is used to calculate the estimated 10 -year survival percentage. ${ }^{25}$ 
117 IBM SPSS Statistics for Windows (SPSS Version 22.0. Armonk, NY: IBM Corp.) was used for the 118 statistical analyses. Independent sample t-test and Mann-Whitney U-test were used for comparison 119 of continuous data and paired EQIndexes were analysed using Wilcoxon test. Binomial variables 120 were analysed with $\chi^{2}$-test. Quality of life index (EQIndex) after CA was dichotomized from 0.885 121 into two equal-sized groups. Forward stepwise binary logistic regression was used to explain higher 122 post-resuscitation EQIndex using initial rhythm (VF vs. ASY/PEA); CCI; ROSC (min); TH; age; $123 \mathrm{PCI} / \mathrm{CABG}$; and EQIndex before $\mathrm{CA}$ as explanatory variables. Results are shown as percentages 124 and numbers of patients, as medians with interquartile range $\left(\mathrm{Q}_{1}, \mathrm{Q}_{3}\right)$ or as means with standard 125 deviations (SD) as appropriate. Results for the binary logistic regression analyses are shown as odds 126 ratios (OR) and 95\% confidence intervals (95\% CI). Two-sided $p<0.05$ was considered 127 statistically significant. 


\section{Results}

130

\section{Patients' Demographics}

During the study period, a total of 222 patients received post-resuscitation care in the ICU. After six months 79/222 (36\%) were alive and 55/79 (70\%) made a post-discharge follow-up visit to the ICU or replied by mail to the EQ-5D questionnaire. Flowchart of the patients admitted to ICU (Fig 1.).

Patients' mean age was 66 (14) years and 42/55 (76\%) were male. The percentages of CCI were 0: $33 \%, 1-2: 48 \%, \geq 3: 19 \% .56 \%$ of all the patients were estimated to survive 10 years according to CCI. ROSC was achieved in $13(8,25)$ minutes. TH was used for $28(51 \%)$, CABG/PCI was done for $15(27 \%)$ and ICD/PAMA was implanted for 17 (31\%) patients. There were no statistically significant differences in age, gender dispersion, number of comorbidities, estimated 10-year survival, EQIndex prior to cardiac arrest and time to return of spontaneous circulation between patients who answered to the questionnaire and patients who did not. Patients' characteristics are shown in Table 1.

OHCA patients represented $64 \%(35 / 55)$ of the study population. In OHCA patients ROSC was achieved in $19 \min [11.0,31.0]$ whereas in IHCA patients it was achieved in $7.5 \min [5.25,12.25]$ $(p<0.001)$. OHCA patients had less comorbidities than IHCA patients $(\mathrm{p}=0.04)$ and $64 \%$ of the OHCA patients were estimated to survive 10 years whereas the corresponding percentage for IHCA patients was $41 \%(p=0.02)$. TH was used for $66 \%$ of OHCA and $25 \%$ of IHCA patients $(p=0.004)$. A similar difference was also seen in revascularization procedures: 14/35 (40\%) of OCHA patients had either PCI or CABG, but only $1 / 20$ (5\%) of IHCA patients underwent CABG $(p=0.005)$.

\section{Details of these patient/treatment groups are shown in Table 1. We observed no statistically} significant differences in the quality of life, gender or age between the cardiac patients treated with revascularization procedure or therapeutic hypothermia and those who were not. 
153 Quality of Life

154 The values for EQIndex for all the patients before and after CA were $0.89[0.63,1]$ and $0.89[0.62$, 155 1] $(p=0.75)$, respectively. Pre- and post-CA QoL parameters are shown in Table 2.

156 Table 3 presents the results from the binomial multivariable logistic regression model assessing the 157 association between post-CA EQIndex and possible predictive factors. Higher EQIndex values prior 158 to CA were associated with increased odds of EQIndex post-CA (OR 1.2; 95\% CI 1.0 - 1.3;

$159 \mathrm{p}=0.02$ ). Subgroup analysis of patients with cardiac reasons and non-cardiac reasons for CA yielded 160 similar results. 


\section{Discussion}

163 This study demonstrates that in survivors responding to the questionnaire the overall quality of life

164 after CA is comparable to the pre-CA evaluation. Our results concur with earlier reports, although

165 direct comparisons are difficult due to differences in quality of life scales and because many studies

166 have not considered pre-CA quality of life. ${ }^{2-6}$ Quality of life prior to CA remained the only

167 significant factor predicting better quality of life after CA. Interestingly, patients surviving CA

168 seemed to have a better quality of life before and after CA than their peers in general Finnish

169 population. $^{26}$

170 Research has shown that OHCA patients presenting with VF as initial rhythm have the best

171 prognoses for survival and good quality of life. ${ }^{27-30}$ In our study the EQIndex values were similar

172 before and after CA in VF patients. Patients with VF had higher EQIndex values after CA than

173 patients presenting with PEA/ASY. However, VF patients had higher EQIndex values than the

174 others already prior to CA.

175 Our study confirms the findings that, compared to surviving IHCA patients, cardiac causes as

176 aetiology and VF as initial rhythm are more common in OHCA patients. ${ }^{31-35}$ In a study published by

177 Bergum et al. cardiac causes explained $60 \%$ of all IHCA cases and $30 \%$ of discharged patients had

178 a cardiac cause for CA. ${ }^{36}$ Less than half of surviving IHCA patients had a cardiac cause for CA and

179 non-shockable rhythms predominated in the IHCA patients. However, the question remains whether

180 all cardiac patients at risk for CA are properly identified in hospital. Although the patients are of

181 similar age, many diseases are overrepresented in IHCA patients and the estimated 10-year survival

182 is lower in IHCA than in OHCA patients. Majority of IHCA patients had comorbidity index 2 or

183 more predicting increased mortality following intensive care. ${ }^{24}$ 
Callaway et al. reported in 2014 that early coronary intervention and induced hypothermia were associated with favourable functional status measured with modified Rankin Score in OCHA patients. ${ }^{37}$ However, this study lacks the vital information on the patients' functional status prior to CA. Subgroup analysis in our study showed that patients selected for invasive cardiac procedures were associated with higher EQIndex after CA compared to those without invasive cardiac procedures. No difference was seen in pre-CA EQIndexes, but the patients selected for TH had higher EQIndex and lower CCI before CA than patients treated without $\mathrm{TH}$. The patients treated with $\mathrm{TH}$ had no change in EQIndex after CA, but the patients treated with conservative methods had better EQIndex after than before CA. However, when all possible factors influencing the outcome were considered, the only factor which demonstrably predicted better quality of life after CA in the multivariate analysis was good quality of life prior to CA. It would be very important in future studies to report quality of life and comorbidities before and after any invasive treatment to be able to analyse the possible effect of different interventions on patient outcome.

Our study has some limitations. Because this was a retrospective study, we could not retrieve all data pertinent for the study. Furthermore, 24 patients out of 79 did not complete the EuroQoL questionnaire. We can only guess the reasons. Whether the missing data from the $30 \%$ of the patients represent a group with poor quality of life with high dependence on continuous support remains unresolved. On the other hand, quality of life was analysed only for those patients with data available both before and after CA. The total number of patients was rather small. Therefore, it is prudent to state that caution should be exercised in the interpretation and extrapolation of the data. It must also be emphasized that EQIndex does not directly correlate with the patient's cognitive outcome.

We conclude that in this highly selected group, the quality of life six months after CA was surprisingly good in CA survivors, even in those with numerous comorbidities. The best predictor 
208 for good quality of life after CA was good quality of life prior to CA. In future studies, it is prudent 209 to include pre-CA quality of life into analyses when assessing the possible benefits of targeted 210 temperature management and other invasive treatments, such as coronary interventions. 
214 Dr. Jyrki Tenhunen has been a member of the SuPAR-Symposium organizing committee for 215 SuPARnostic (Virogates, Copenhagen, Denmark) and co-founder and shareholder of SenSem 216 Technologies (Tampere, Finland) and Medieta Ltd (Helsinki, Finland).

217 The other authors declare no conflicts of interest.

\section{Acknowledgments}

220 We would like to acknowledge the Tays ICU patient data management system controllers, who 221 helped us gather all the information concerning EQ-5D questionnaires and we are eternally grateful 222 for that.

223 This study was funded by the Instrumentarium Science Foundation, Helsinki, Finland and by the 224 Competitive Research Funding of Tampere University Hospital (Grant 9M105). The funding 225 organizations had no involvement in any aspect of the study. 
1. Wong M, Morrison LJ, Qiu F, Austin PC, Cheskes S, Dorian P, Scales DC, Tu JV, Verbeek PR, Wijeysundera HC, Ko DT. Trends in Short- and Long-Term Survival Among Out-of-Hospital Cardiac Arrest Patients Alive at Hospital Arrival. Circulation 2014; 130: 1883-90.

2. Meaney PA, Bobrow BJ, Mancini ME, Christenson J, de Caen AR, Bhanji F, Abella BS, Kleinman ME, Edelson DP, Berg RA, Aufderheide TP, Menon V, Leary M; CPR Quality Summit Investigators, the American Heart Association Emergency Cardiovascular Care Committee, and the Council on Cardiopulmonary, Critical Care, Perioperative and Resuscitation. Cardiopulmonary Resuscitation Quality: Improving Cardiac Resuscitation Outcomes Both Inside and Outside the Hospital: A Consensus Statement From the American Heart Association. Circulation 2013; 128 : 417-35.

3. Elliott VJ, Rodgers DL, Brett SJ. Systematic review of quality of life and other patient-centred outcomes after cardiac arrest survival. Resuscitation 2011; 82: 247-56.

4. Beesems SG, Wittenbrood KM, de Haan RJ, Koster RW. Cognitive function and quality of life after successful resuscitation from cardiac arrest. Resuscitation 2014; 84: 1269-74.

5. Smith K, Andrew E, Lijovic M, Nehme Z, Bernard S. Quality of Life and Functional Outcomes 12 Months After Out-of-Hospital Cardiac Arrest. Circulation 2015; 131: 174-81.

6. Haydon G, van der Riet P, Maguire J. Survivors' quality of life after cardiopulmonary resuscitation: an integrative review of the literature. Scand J Caring Sci. 2017; 31: 6-26.

7. Granja C, Cabral G, Pinto AT, Costa-Pereira A. Quality of life 6 months after cardiac arrest. Resuscitation 2002; 55: 37-44.

8. Felce D, Perry J. Quality of Life: Its Definition and Measurement. Research in Developmental Disabilities 1995; 16: 51-74.

9. Ware EW. Measuring functioning, well-being and other generic health concepts. In: Osoba D, editor. Effect of Cancer of Quality of Life. Boca Raton (FL): CRC Press, 1991: 7-24.

10. Guyatt GH, Cook DJ. Health status, quality of life and the individual. J Am Med Assoc. 1994; 272: 630-1.

11. Brooks R, the EuroQol Group. EuroQol: the current state of play. Health Policy 1996; 37: 5372.

12. Hays RD, Sherbourne CD, Mazel RM. The rand 36-item health survey 1.0. Health Economics 2006; 2: 217-27.

13. World Health Organization (1993). WHOQoL Study Protocol. WHO (MNH7PSF/93.9). http:// http://www.who.int/substance_abuse/research_tools/whoqolbref/en/

14. Gamper G, Willeit M, Sterz F, Herkner H, Zoufaly A, Hornik K, Havel C, Laggner AN. Life after death: posttraumatic stress disorder in survivors of cardiac arrest - prevalence, associated factors, and the influence of sedation and analgesia. Crit Care Med 2004; 32: 378-83.

15. Cronberg T, Lilja G, Rundgren M, Friberg H, Widner H. Long-term neurological outcome after cardiac arrest and therapeutic hypothermia. Resuscitation 2009; 80: 1119-23. 
16. Charlson ME, Pompei P, Ales KL, MacKenzie CR. A new method of classifying prognostic comorbidity in longitudinal studies: development and validation. J Chronic Dis 1987; 40: 373-83.

17. Hellevuo H, Sainio M, Nevalainen R, Huhtala H, Olkkola KT, Tenhunen J, Hoppu S. Deeper chest compression - More complications for cardiac arrest patients? Resuscitation 2013; 84: 760-5.

18. Setälä P, Hoppu S, Virkkunen I, Yli-Hankala A, Kämäräinen A. Assessment of futility in outof-hospital cardiac arrest. Acta Anaesthesiol Scand. 2017; 61: 1334-44.

19. Badia X, Díaz-Prieto A, Rué M, Patrick DL. Measuring health and health state preferences among critically ill patients. Intensive Care Med. 1996; 22: 1379-84.

20. Badia X. Diaz-Prieto A. Gorriz MT, Herdman M, Torrado H, Farrero E, Cavanilles JM. Using the EuroQol-5D to measure changes in quality of life 12 months after discharge from an intensive care unit. Intensive Care Med 2001; 27: 1901-7.

21. Norena M, Wong H, Thompson WD, Keenan SP, Dodek PM. Adjustment of intensive care unit outcomes for severity of illness and comorbidity scores. J Crit Care 2006; 21: 142-50.

22. D'Hoore W, Sicotte C, Tilquin C. Risk adjustment in outcome assessment: the Charlson comorbidity index. Methods Inf Med 1993; 32: 382-7.

23. Poses RM, McClish DK, Smith WR, Bekes C, Scott WE. Prediction of survival of critically ill patients by admission comorbidity. J Clin Epidemiol 1996; 49: 743-7.

24. Christensen S, Johansen MB, Christiansen CF, Jensen R, Lemeshow S. Comparison of Charlson comorbidity index with SAPS and APACHE scores for prediction of mortality following intensive care. Clin Epidemiology 2011; 3: 203-11.

25. Age adjusted Charlson Comorbidity Index. http://tools.farmacologiaclinica.info/index.php. (used 20.5.2014)

26. Koskinen S, Lundqvist A, Ristiluoma N. Health, functional capacity and welfare in Finland in 2011. National Institute for Health and Welfare (THL), Report 68/2012. Helsinki 2012. ISBN 978952-245-768-4 (printed), ISBN 978-952-245-769-1 (online publication). www.julkari.fi/bitstream/handle/10024/90832/Rap068_2012_netti.pdf (read 12.3.2015)

27. Atwood C, Eisenberg M, Herlitz J, Rea T: Incidence of EMS-treated out-of hospital cardiac arrest in Europe. Resuscitation 2005; 67: 75-80.

28. Väyrynen T, Kuisma M, Määttä T, Boyd J. Who survives from out-of-hospital pulseless electrical activity? Resuscitation 2008; 76: 207-31.

29. Hallstrom A, Rea T, Mosesso V Jr, Cobb LA, Anton AR, Van Ottingham L, Sayre MR, Christenson J. The relationship between shocks and survival in out-of-hospital cardiac arrest patients initially found in PEA or asystole. Resuscitation 2007; 74: 418-26.

30. Rea T, Eisenberg M, Sinibaldi G, White RD. Incidence of EMS-treated out-of-hospital cardiac arrest in the United States. Resuscitation 2004; 63: 17-24.

31. Pell JP, Sirel JM, Marsden AK, Ford I Walker NL, Cobbe SM. Presentation, management, and outcome of out of hospital cardiopulmonary arrest: comparison by underlying aetiology. Heart 2003; 89: 839-2. 
32. Kuisma M, Repo J, Alaspää A. The incidence of out-of-hospital ventricular fibrillation in Helsinki, Finland, from 1994 to 1999. Lancet 2001; 358: 473-4.

33.Wissenberg M, Lippert FK, Folke F, Weeke P, Hansen CM, Christensen EF, Jans H, Hansen PA, Lang-Jensen T, Olesen JB, Lindhardsen J, Fosbol EL, Nielsen SL, Gislason GH, MD, Kober L, Torp-Pedersen C. Association of National Initiatives to Improve Cardiac Arrest Management With Rates of Bystander Intervention and Patient Survival After Out-of-Hospital Cardiac Arrest. JAMA 2013; 310: 1377-84.

34. Peberdy MA, Kaye W , Ornato JP , Larkin GL , Nadkarni V , Mancini ME, Berg RA, Nichol G, Lane-Trultt T. Cardiopulmonary resuscitation of adults in the hospital: a report of 14720 cardiac arrests from the National Registry of Cardiopulmonary Resuscitation. Resuscitation 2003; 58: 297 308.

35. Skrifvars M, Pettilä V, Rosenberg PH, Castrén M. A multiple logistic regression analysis of inhospital factors related to survival at six months in patients resuscitated from out-of-hospital ventricular fibrillation. Resuscitation 2003; 59: 319-28.

36. Bergum D, Nordseth T, Mjølstad OC, Skogvoll E, Haugen BO. Causes of in-hospital cardiac arrest - Incidences and rate of recognition. Resuscitation 2015; 87: 63-8.

37. Callaway CW, Schmicker RH, Brown SP, Albrich JM, Andrusiek DL, Aufderheide TP, Christenson J, Daya MR, Falconer D, Husa RD, Idris AH, Ornato JP, Rac VE, Rea TD, Rittenberger JC, Sears G, Stiell IG; ROC Investigators. Early coronary angiography and induced hypothermia are associated with survival and functional recovery after out-of-hospital cardiac arrest Resuscitation 2014; 85: 657-63. 
Table 1 Characteristics of the patients

\begin{tabular}{|c|c|c|c|c|}
\hline Variables & $\begin{array}{l}\text { Study population } \\
\mathrm{n}=55(\%)\end{array}$ & $\begin{array}{l}\text { IHCA } \\
n=20(36)\end{array}$ & $\begin{array}{l}\text { OHCA } \\
\mathrm{n}=35(64)\end{array}$ & $p$-value \\
\hline Age & $68[60,77]$ & $72[64,80]$ & $65[60,73]$ & 0.11 \\
\hline Gender, male (\%) & $42(76)$ & $14(70)$ & $28(80)$ & 0.51 \\
\hline \multicolumn{5}{|l|}{$\mathrm{CCI}^{\mathrm{a}}(\%)$} \\
\hline Index value 0 & $18(33)$ & $4(20)$ & $14(40)$ & 0.04 \\
\hline Index value $1-2$ & $26(48)$ & $9(45)$ & $17(49)$ & 0.05 \\
\hline Index value $\geq 3$ & $11(19)$ & $7(35)$ & $4(11)$ & 0.68 \\
\hline Estimated 10 y survival (\%) & $56(33)$ & $41(36)$ & $64(29)$ & 0.02 \\
\hline Pre-CA EQIndex ${ }^{\mathrm{b}}$ & $0.89[0.63,1]$ & $0.85[0.63,0.92]$ & $0.89[0.72,1]$ & 0.36 \\
\hline Post-CA EQIndex ${ }^{\mathrm{c}}$ & $0.89[0.62,1]$ & $0.85[0.62,0.92]$ & $0.89[0.71,1]$ & 0.34 \\
\hline ROSC, $\min$ & $13[8.0,25.0]$ & $7.5[5.3,12.3]$ & $19.0[11.0,31.0]$ & $<0.001$ \\
\hline $\mathrm{TH}^{\mathrm{d}}(\%)$ & $28(51)$ & $5(25)$ & $23(66)$ & 0.004 \\
\hline Revascularization ${ }^{\mathrm{e}}(\%)$ & $15(27)$ & $1(5)$ & $14(40)$ & 0.005 \\
\hline ICD/PAMA (\%) & $17(31)$ & $3(15)$ & $14(40)$ & 0.05 \\
\hline \multicolumn{5}{|l|}{ Cause of CA } \\
\hline - Cardiac origin $(\%)$ & $37(67)$ & $8(40)$ & $29(83)$ & 0.001 \\
\hline - Non-cardiac origin $(\%)$ & $18(33)$ & $12(60)$ & $6(17)$ & 0.001 \\
\hline \multicolumn{5}{|l|}{ Initial rhythm } \\
\hline - Shockable rhythm (\%) & $36(65)$ & $6(30)$ & $30(86)$ & $<0.001$ \\
\hline Non-shockable rhythm (\%) & $19(35)$ & $14(70)$ & $5(14)$ & $<0.001$ \\
\hline
\end{tabular}


Table 2

Quality of life index prior to cardiac arrest and six months after cardiac arrest

\begin{tabular}{lllc}
\hline Variables & $\begin{array}{l}\text { Pre-CA } \\
\text { EQIndex }\end{array}$ & $\begin{array}{l}\text { Post-CA } \\
\text { EQIndex }\end{array}$ & p-value \\
\hline All patients, $\mathrm{n}=55$ & $0.89[0.63,1]$ & $0.89[0.62,1]$ & 0.75 \\
OHCA patients, $\mathrm{n}=35$ & $0.89[0.72,1]$ & $0.89[0.71,1]$ & 0.19 \\
IHCA patients, $\mathrm{n}=20$ & $0.85[0.63,0.92]$ & $0.85[0.62,0.92]$ & 0.24 \\
Cause of CA & & & \\
$\quad$ - Cardiac, $\mathrm{n}=37$ & $0.89[0.75,1]$ & $0.89[0.78,1]$ & 0.62 \\
- Other reason, $\mathrm{n}=18$ & $0.61[0.57,0.85]$ & $0.72[0.45,0.92]$ & 0.75 \\
Initial rhythm & & & \\
- Shockable rhythm, $\mathrm{n}=36$ & $0.89[0.78,1]$ & $0.89[0.81,1]$ & 0.22 \\
- Non-shockable rhythm, $\mathrm{n}=19$ & $0.63[0.56,0.89]$ & $0.75[0.45,0.92]$ & 0.68 \\
Therapeutic hypothermia & & & \\
- Yes & $0.89[0.63,1]$ & $0.89[0.75,1]$ & 0.35 \\
- No & $0.81[0.70,0.92]$ & $0.89[0.53,0.92]$ & 0.59 \\
Revascularization & & & \\
$-\quad$ Yes & $0.89[0.81,1]$ & $1[0.92,1]$ & 0.91 \\
- No & $0.89[0.70,1]$ & $0.89[0.81,1]$ & 0.69 \\
\hline
\end{tabular}

The data presented as medians [Interquartiles].

EQIndex: Quality of life Index (0-1) 
Table 3

Association of different variables with post-CA EQIndex

Variable Univariable regression

\begin{tabular}{lll} 
& OR $(95 \% \mathrm{CI})^{*}$ & p-value \\
\hline Pre-CA EQIndex & $1.2(1.0-1.3)$ & 0.02 \\
Age, Y & $1.1(0.9-1.2)$ & 0.09 \\
CCI & $1.2(0.6-2.6)$ & 0.62 \\
Initial rhythm, VF or PEA/ASY & $0.6(0.2-1.9)$ & 0.25 \\
ROSC (min) & $1.1(0.9-1.1)$ & 0.11 \\
Revascularization (PCI/CABG) & $2.2(0.3-2.9)$ & 0.38 \\
Therapeutic hypothermia YES NO & $1.1(0.8-3.1)$ & 0.09 \\
\hline *Odds ratio with 95\% Confidence Interval & \\
\hline
\end{tabular}


Fig 1. Flowchart of the patients

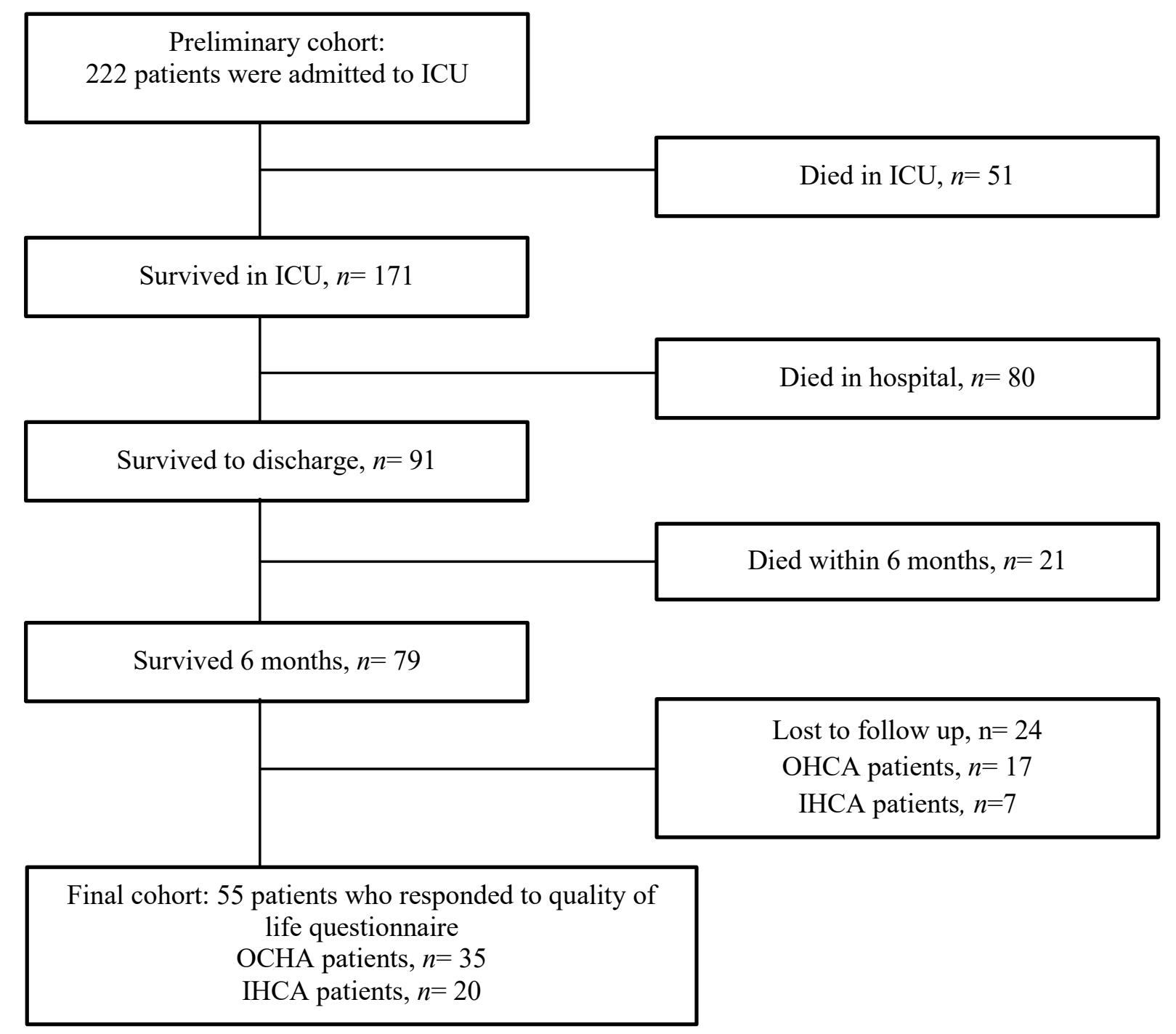

